\title{
Variability of Quantitative Digital Subtraction Coronary Angiography Before and After Percutaneous Transluminal Coronary Angioplasty
}

\author{
MARK L. SANZ, MD, G.B. JOHN MANCINI, MD, MICHAEL T. LeFREE, BS, \\ JUDITH K. MICKELSON, MD, MARK R. STARLING, MD, ROBERT A. VOGEL, MD, \\ and ERIC J. TOPOL, MD
}

Quantitative coronary angiography has been proposed as a means of reducing observer variability in the interpretation of coronary angiograms, especially before and after percutaneous transluminal coronary angioplasty (PTCA). Analysis of 13 consecutively acquired biplane digital subtraction angiograms before and after PTCA was undertaken to determine intra- and interobserver variability of absolute lesion diameter, relative videodensitometric cross-sectional area, automated percent diameter stenosis and visual percent diameter stenosis using a new fully automated quantitative computer program. The reliability of single-view measurements was also assessed. Both before and after PTCA, measures of absolute diameter showed less interobserver variability than densitometry, percent automated diameter stenosis and percent visual diameter stenosis measurements (before, $r=0.95,0.83,0.86,0.70$; after, $0.95,0.88,0.81,0.62$, respectively). Relative videodensitometric cross-sectional area correlated poorly with images from the orthogonal view $(r=$ $0.46)$. These data suggest that quantitative angiography reduces variability from visual estimates; of all quantitative angiographic measurements, the highest interobserver reproducibility is achieved using absolute lesion diameter both before and after PTCA, probably because no operator interaction is needed to identify a "normal" segment. Unselected, single-view quantitative arteriography is poorly reproducible using videodensitometry. Therefore, auto mated determination of absolute lesion diameter in at least 2 projections provides the most reproducible evaluation of coronary lesions both before and after PTCA.
V

isual evaluation of $35-\mathrm{mm}$ coronary cineangiograms has a large inter- and intraobserver variability. ${ }^{1-5}$ To evaluate the natural history of coronary artery disease or effects of various therapeutic regimens, a method of evaluating coronary anatomy that has a low observer variability is needed. Computerized methods have decreased the amount of observer variability. ${ }^{6-13}$ 'There are many methods and degrees of automation in the quantitative analysis of cineangiograms, but few allow

From the Department of Internal Medicine, Division of Cardiology, Veterans Administration Medical Center and University Hospital, University of Michigan Medical School, Ann Arbor, Michigan. The study was supported in part by the Veterans Administration, Washington, D.C. Manuscript received December 1, 1986; revised manuscripl received and accepled February 19, 1987.

Address for reprints: G.B. John Mancini, MD, Ann Arbor Veterans Administration Hospital, Division of Cardiology, 2215 Fuller Road, Ann Arbor, Michigan 48105. for interactive, on-line processing during cardiac catheterization.

In this study inter- and intraobserver variability of on-line, digitally acquired coronary artery images, quantitated with a semiautomatic computer analysis program that performs rapidly enough to be suitable for use during angiography, was assessed. The purpose of this investigation was to determine the degree of improvement in variability provided by automated analyses compared to visual assessment, the relative observer error of videodensitometric percent area stenosis compared to absolute diameter and percent diameter stenosis measurements both before and after angioplasty, and the agreement of videodensitometric percent area stenosis calculations from orthogonal vicws.

\section{Methods}

Patients: Thirteen consecutive patients undergoing elective 1-vessel PTCA were selected on a prospec- 
tive, sequential basis without exclusion. In each patient at least 2 orthogonal right anterior oblique and left anterior oblique views of the coronary lesion were obtained both before and after PTCA, yielding a total of 52 images. Patients were not selected on the basis of ease of computer processing, absence of overlapping vessels, the site or geometry of the coronary lesion or whether angioplasty was successful. Seven patients had left anterior descending artery, 2 circumflex artery, 2 right coronciry artery and 2 graft stenoses. Four patients had intimal dissections after PTCA. Images from 1 patient in the right anterior oblique and left anterior oblique views before and after PTCA are shown in Figure 1 with coronary measurements.

Imaging procedure: Both this procedure and the quantification software have been described. ${ }^{7-9}$
Paired projections that were roughly orthogonal in the right anterior oblique and left anterior oblique views were selected to provide optimal visualization of the stenoses. After the angle of view was selected, images were acquired at $512 \times 512 \times 8$-bit resolution with electrocardiogram-synchronized R-wave gating. Acquisitions were made at end-diastole at 1 image per cycle for 6 to 12 cycles. Hand injection of Renografin ${ }^{\circledR}$ was used.

Images were preprocessed before analysis. The gray scalc of the image was linearly expanded to fill the full 8-bit range of the system. Images were processed using a standard protocol by a cardiologist. The preprocessing included choosing the images for final electrocardiogram-synchronized mask-mode subtraction.

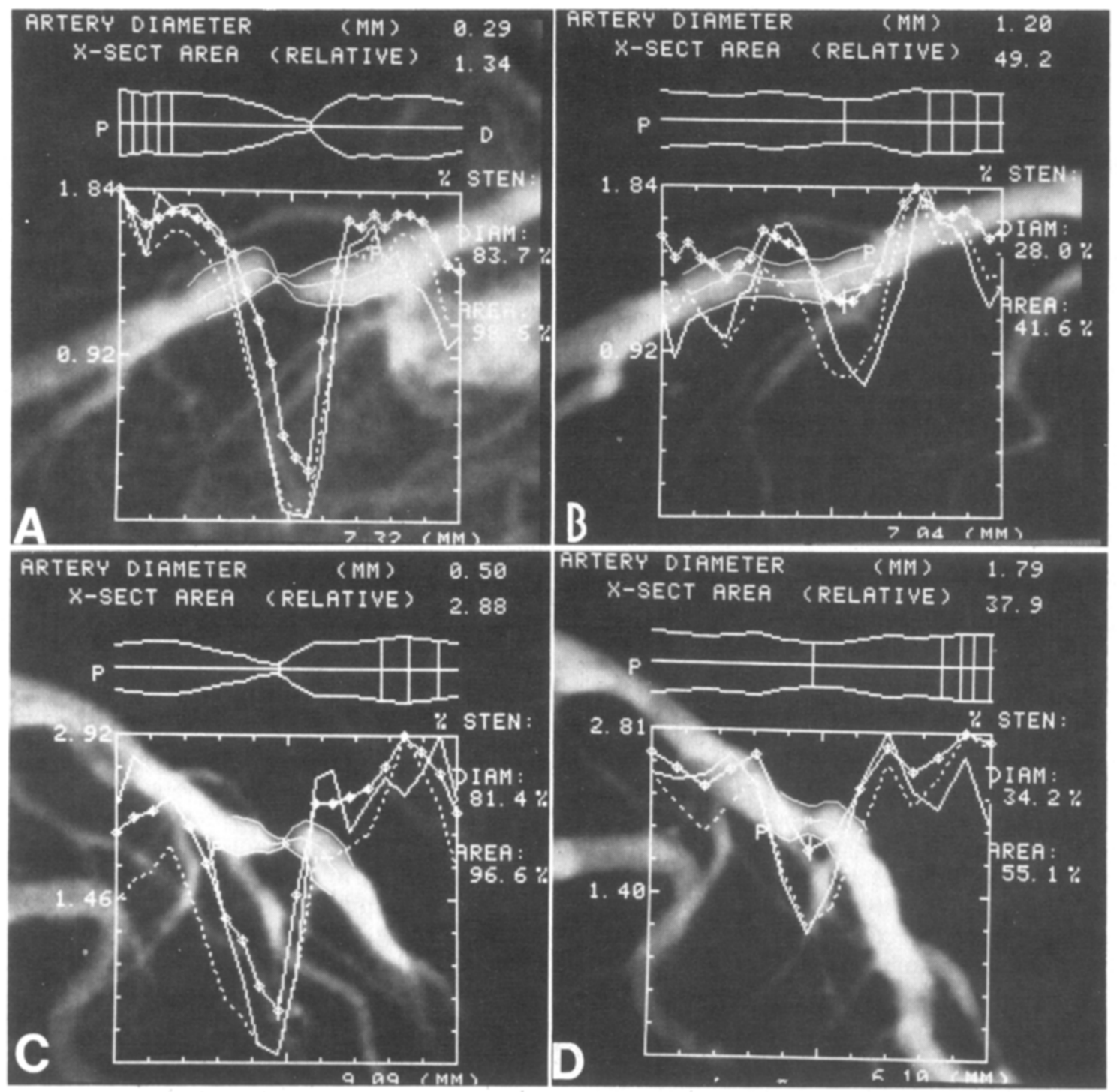

FIGURE 1. Data output overlaid on right anterior and left anterior oblique views of left anterior descending artery stenosis in 1 patient both before and after percutaneous transiuminal coronary angioplasty (PTCA). A, left anterior oblique view before PTCA . B, left anterior oblique view after PTCA. $C$, right anterior oblique view before PTCA. $D$, right anterior oblique after PTCA. Top line of overlay displays minimal diameter at stenosis in millimeters. Below minimal diameter and cross-sectional ( $X$-sect) area, the stylized, straightened artery shows positions of "normal" segments at proximal (P) end of artery and position of stenosis in middle of artery. Relative diameter and densitometric area stenosis are shown to the right. Dashed line indicates percent diameter stenosis along artery; dotted line relative densitometric area stenosis along artery; dashed-dotted line relatlve area stenosis assuming circular geometry. 
Quantification software: The operators identified a circular region of interest region centered on the lesion within each of the 52 images using a light-pen cursor and adjusting the radius of the region of interest to contain the stenotic and "normal" segments of artery to be analyzed. The software then proceeded without operator interaction. Arterial centerline analysis was performed, followed by extraction of linear density profiles perpendicular to the centerline over the length of the arterial segment within the region. Fdge detection was automatically performed in 2 passes over the density profiles by initially using intensity gradient information. Spurious edge points are discarded using a spatial continuity criterion. If adjacent gradient-determined edge points fall a distance greater than a preset pixel distance from each other, they are discarded. The second pass replaces the discarded points using local threshold information, interpolated from the intensity thresholds of adjacent valid edge points.

The analysis software automatically identifies a proximal and distal end, a normal segment and the point of maximal stenosis. However, if necessary, the operator could redefine the "normal" or stenotic segment. This was used most often to define the site of stenosis after PTCA, to ensure comparability of measurements among observers in complex post-PTCA images. An independent cardiologist identified the location of the lesion for the operator in post-PTCA images where ambiguities were noted because of a lack of an obvious site of stenosis in some patients.

Absolute measurements of stenosis diameter were obtained by using the catheter as a scaling device. The pixel diameter of the catheter was measured before mask-mode subtraction using the same edge-detection program as described herein. The total time for processing and analysis of a single image was 1 to 2 minutes.

Coronary measurements: Three cardiologists analyzed each image independently. Images were recorded as being before or after PTCA and as right anterior oblique or left anterior oblique projections. The results from the 2 views were not combined. The following data were obtained from each image by each cardiologist: percent diameter stenosis, absolute lesion diameter, videodensitometric relative cross-sectional area and a visual estimation of percent lesion diameter before computer analysis.

Multiple-view variability was assessed by analyzing 42 images in 2 views by 2 observers (see Results section for causes of image exclusions]. Analysis was performed by comparing each observer's videodensitometric cross-sectional area or percent diameter stenosis results in the right vs left anterior oblique view. Intraobserver variability was analyzed in the 13 arteries in both views and before and after angioplasty, yielding 91 analyzable images. They were quantified by 1 observer 2 weeks apart in a different random order during each session. Interobserver variability was examined for percent diameter stenosis, videodensitometric cross-sectional area stenosis and absolute diameter. Each measurement was analyzed both before and after PTCA. To determine the variability of
TABLE \& Absolute Diameter (Millimeters) interobserver Variability

\begin{tabular}{lcccc}
\hline Type & $\begin{array}{c}\text { No. of } \\
\text { Projections }\end{array}$ & r Value & SD (mm) & Slope \\
\hline Overall & 45 & 0.97 & 0.19 & 0.97 \\
Before PTCA & 24 & 0.95 & 0.16 & 0.96 \\
After PTCA & 21 & 0.95 & 0.23 & 0.95 \\
\hline
\end{tabular}

$S D=$ standard deviation

visual estimation of percent diameter stenosis, 2 of 3 observers were asked to estimate the percent diameter stenosis on the processed magnified image before beginning analysis. Forty-five images were analyzed by both observers. Absolute diameter variability was also assessed.

Statistical analysis: Standard linear regression analysis was performed. The interobserver analysis was compared among the 3 cardiologists. The statistical significance of any differences in the 3 regression slopes and intercepts was tested using covariance analysis. Intraobserver variability was tested by linear regression analysis. Fisher's Z transformation was used to compare correlation coefficients. Interclass coefficients were calculated between the 3 observers for the interobserver variability and also for the 3 linear regressions. ${ }^{14}$ Results are considered significant at the $\mathrm{p}<0.05$ level.

\section{Results}

Technical problems: Some images could not be analyzed: in 1 image a pacemaker wire obscured a lesion, 1 image set had inadequate dye opacification and 1 image set showed spatial registration subtraction arti-
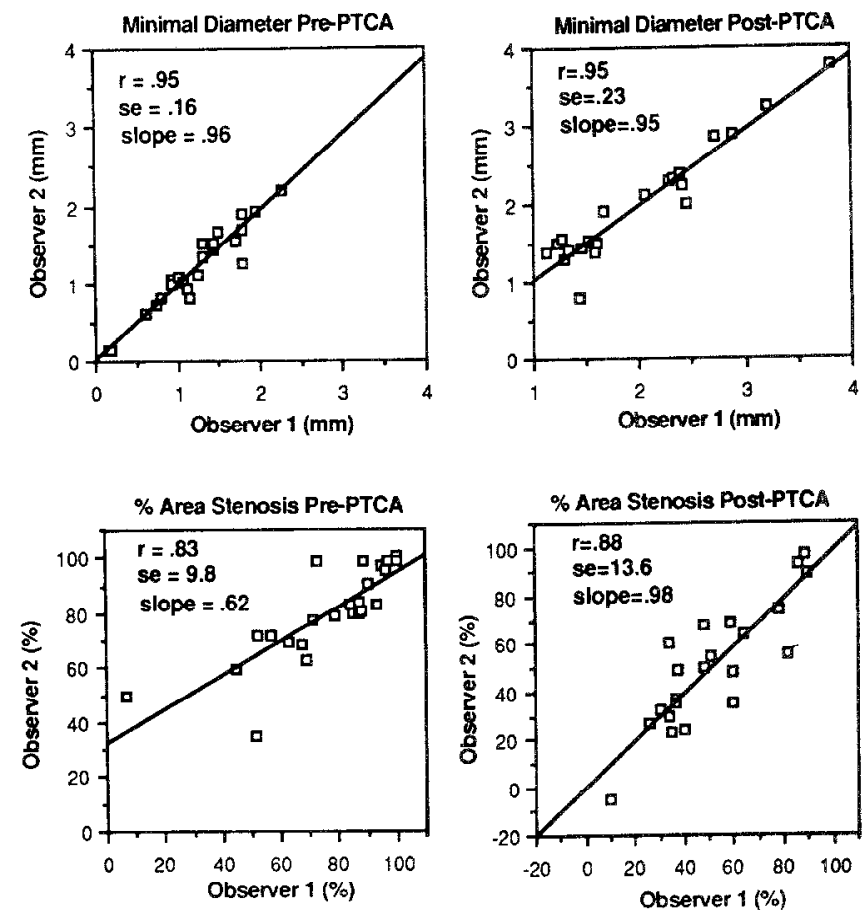

FIGURE 2. Interobserver variability of minimal diameter and percent densitometric area between 2 observers. 
TABLE II Interobserver Variability for Measures of Percent Diameter (Geometric) and Percent Area (Videodensitometric) Measurements

\begin{tabular}{|c|c|c|c|c|c|}
\hline \multirow[b]{2}{*}{ Type } & \multirow{2}{*}{$\begin{array}{c}\text { No. of } \\
\text { Projections }\end{array}$} & \multicolumn{2}{|c|}{ Intraclass $r$ Value } & \multirow[b]{2}{*}{ SD $(\%)$} & \multirow[b]{2}{*}{ Slope } \\
\hline & & Coefficient & Range & & \\
\hline $\begin{array}{l}\% \text { diameter stenosis } \\
\text { (all points) }\end{array}$ & 45 & 0.88 & $0.87-0.91$ & $9.5-11.0$ & $0.90-1.0$ \\
\hline $\begin{array}{l}\% \text { area stenosis } \\
\text { (all points) }\end{array}$ & 45 & 0.89 & $0.87-0.90$ & $10.7-12.9$ & $0.85-0.90$ \\
\hline \multicolumn{6}{|l|}{$\%$ area stenosis } \\
\hline Before PTCA & 23 & 0.83 & $0.82-0.88$ & $8.2-11.0$ & $0.62-0.85$ \\
\hline After PTCA & 22 & 0.88 & $0.86-0.90$ & $10.7-13.6$ & $0.78-0.97$ \\
\hline \multicolumn{6}{|l|}{$\%$ diameter stenosis } \\
\hline Before PTCA & 23 & 0.86 & $0.76-0.94$ & $6.6-13.0$ & $0.79-0.99$ \\
\hline After PTCA & 22 & 0.81 & $0.76-0.88$ & $9.1-12.1$ & $0.92-0.98$ \\
\hline
\end{tabular}

$\mathrm{SD}=$ standard deviation (\% stenosis)

TABLE III Intraobserver Variability for Measures of Percent Diameter (Geometric) and Percent Area (Videodensitometric) Measurements

\begin{tabular}{lcccc}
\hline Type & $\begin{array}{c}\text { No. of } \\
\text { Projections }\end{array}$ & r Value & SD (\%) & Slope \\
\hline $\begin{array}{l}\% \text { diameter stenosis } \\
\text { (all points) }\end{array}$ & 46 & 0.92 & 8.5 & 0.88 \\
$\begin{array}{l}\% \text { area stenosis } \\
\text { (all points) }\end{array}$ & 45 & 0.89 & 11.7 & 0.87 \\
$\%$ area stenosis & & & & \\
$\quad$ Before PTCA & 23 & 0.91 & 8.0 & 1.03 \\
$\quad$ After PTCA & 22 & 0.80 & 13.8 & 0.70 \\
$\%$ diameter stenosis & 24 & $0.96 *$ & 5.5 & 0.96 \\
$\quad$ Before PTCA & 22 & 0.78 & 9.7 & 0.65 \\
$\quad$ After PTCA & & & & \\
\hline
\end{tabular}

* $p<0.005$ for percent diameter stenosis before percutaneous transluminal coronary angioplasty.

$\mathrm{SD}=$ standard deviation ( $\%$ stenosis $)$.

fact subtraction artifact over the lesion and inadequate dye opacification.

Absolute diameter interobserver variability: Correlations in this group were highest among all measurements made. Table I shows the statistical results in this group. Overall correlation (before and after PTCA) was excellent ( $r=0.97)$. In the top 2 graphs of Figure 2 are plots of minimal diameter measured by 1 observer vs another both before and after PTCA showing the excellent correlation among observers. Thus, the highest reproducibility is achieved using absolute diameter measurements both before and after PTCA.

Interobserver variability: Table II contains the data for analyses between the 3 observers. Ranges for the standard deviation, slope of the regression lines and correlation coefficients for the 3 paired regression analyses are shown. For comparison, $r$ values of visual diameter estimates were 0.70 and 0.62 [slopes 0.68 and 0.78) before and after PTCA, respectively.

Figure 2 shows 1 of the videodensitometric area regression plots both before and after PTCA for comparison with the minimal diameter plots above. The correlation coefficient before PTCA is significantly better using measurements of minimal diameter than
TABLE IV Orthogonal View Variability (Right Anterior Oblique vs Left Anterior Oblique)

\begin{tabular}{lcccc}
\hline Type & $\begin{array}{c}\text { No. of } \\
\text { Projections }\end{array}$ & r Value & SD (\%) & Slope \\
\hline $\begin{array}{l}\text { area stenosis } \\
\text { (all points) }\end{array}$ & 42 & 0.46 & 20.5 & 0.36 \\
$\quad$ Before PTCA & 22 & 0.38 & 13.3 & 0.22 \\
After PTCA & 20 & 0.07 & 20.1 & 0.05 \\
\hline
\end{tabular}

$\mathrm{SD}=$ standard deviation (\% stenosis).

densitometric area ( $p<0.03$ ), but not after PTCA ( $p$ $<0.10]$ for the same 2 observers performing both analyses.

The overall variability of densitometric area, automated percent diameter and visual estimate of percent diameter stenosis are similar. Variability in the subcatcgorics of before vs after PTCA was poorer, but there was no significant difference in the correlation coefficient compared with visual estimation of percent diameter stenosis $(p=0.66)$.

Intraobserver variability (Table III): Low variability was found for both percent diameter and crosssectional area reduction (diameter, $\mathrm{r}=0.92,8.5 \%$ standard deviation; area, $\mathrm{r}=0.89,11.7 \%$ standard deviation). There was no significant difference between cross-sectional area variabilities before and after PTCA ( $p=0.18$ ). However, percent diameter stenosis measurements before PTCA were significantly less variable than after PTCA ( $p<0.005)$.

Measures from orthogonal views: Correlations were poor for videodensitometric percent area measurements both before and after PTCA (Table IV). Figure 3 shows a plot of right anterior oblique vs left anterior oblique overall videodensitometric relative cross-sectional area stenosis showing the wide variability for each measurement.

\section{Discussion}

This study examined the variability associated with quantification of on-line coronary angiograms obtained in the setting of routine coronary angioplasty. Previous work using this computer program has vali- 
dated the software using arterial phantoms $\mathrm{s}^{7,8}$ and in an vivo dog model using calibrated beads in the coronary artery. ${ }^{9}$

Some investigators have shown that of several quantitative variables, minimal cross-sectional area is the greatest predictor of the functional significance of a lesion as assessed by coronary flow reserve measurements. ${ }^{15}$ Other investigators have shown the clinical value of quantitative measurements in PTCA during acute myocardial infarction to predict reocclusion ${ }^{16}$ and improvement in left ventricular function. ${ }^{17}$ Thus, the ability to quantitate coronary arterial measurements may be of both diagnostic and prognostic significance. The system of on-line digital image acquisition and live-time processing provides rapid quantitative arteriographic results during an interventional catheterization and this may obviate delays in deciding upon a therapeutic course.

Absolute versus relative measurements: A significant improvement in variability using absolute diameter measurements versus relative diameter stenosis was noted. There was no statistical difference, however, in the variability associaled with using visual versus digital percent diameter stenosis measurements ( $p=0.23$ ). This is likely because absolute measurements do not require identification of a "normal" segment. Other computer analysis programs use interpolated normal segments, ${ }^{18,19}$ although the true edge of the "normal" artery is unknown. Software used in this study allows for user-defined averaging of any portion of the artery as a "normal" segment, but this was not encouraged in this study to avoid variability inherent in this technique.

Future studies examining atherosclerosis progression and regression will need to identify the variability inherent in the method of quantitative coronary angiography. From this study, differences in coronary artery lesion absolute diameter of $0.2 \mathrm{~mm}$ based on the standard deviation of $0.19 \mathrm{~mm}$ can be measured between multiple observers. Similarly, percent diameter stenosis differences greater than $12.0 \%$ can be considered significant. Variability in videodensitometric cross-sectional area stenosis is similar to that of automated percent diameter calculations (12.9\%). This study did not incorporate frame-to-frame variability as might be found in analyzing cineangiograms. In comparison, previous studies using the same software have shown the standard error of absolute diameter of cylindrical phantoms to be $0.15 \mathrm{~mm}$, with an overestimation up to $10 \%$ below $1.0 \mathrm{~mm} .{ }^{8}$ Although larger studies may be needed, the sample size of 52 images from 13 patients in this study clearly shows that absolute diameter before and after PTCA provided the greatest precision in measurements.

Orthogonal view variability: Videodensitometry has been suggested as a means of assessing asymmetric lesions. An important result of this study is the lack of correlation between orthogonal views using videodensitometric measurements. This is in contrast to 2 previous studies. Spears et a ${ }^{13}$ found no effect of field position or orientation on a 3.14-mm-diameter circular phantom study. We believe this discrepancy in results

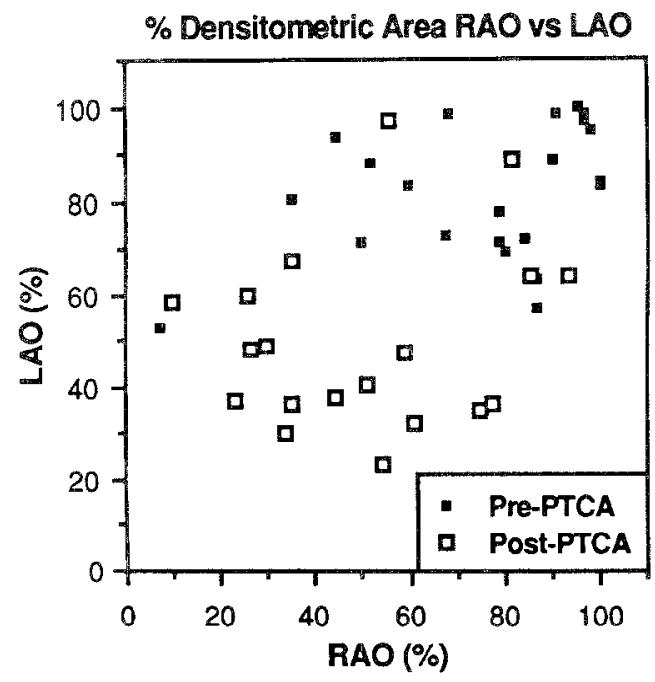

FIGURE 3. Orthogonal view variability of densitometric area stenosis for each observer both before and after percutaneous transluminal angioplasty: $r=0.39,0.07$, slope $=0.22,0.05$, belore and after percutaneous transluminal coronary angioplasty (PTCA). LAO $=$ left anterior oblique; RAO = right anterior oblique.

is due to the perfect concentric geometry of phantoms vs human atherosclerotic coronary vessels. Among factors contributing to the inaccuracy of videodensitometry are beam hardening and x-ray scatter; characteristics of angiographic $\mathrm{x}$-ray systems such as veiling glare, the nonuniform brightness and contrast response of the image intensifier; and potential sources of nonlinearity in digital radiographic systems such as video camera alignment and logarithmic compensation for Lambert-Beer x-ray absorption. When these factors are combined with geometric considerations of alignment of arteries and asymmetric stenotic lesions, it is not surprising that videodensitometric results may be inaccurate. Nichols et a ${ }^{12}$ found a very high correlation ( $r=0.99$, SEE 2.8\%) for right vs left anterior oblique images of 10 coronary arteries. Only selected non-angioplasty arteries were used, however, for analysis where the selected views were chosen to display the long axis of the segment without foreshortening. Many, if not most, coronary arteries cannot be imaged with both the lesion and a "normal" segment in a nonforeshortened view. In addition, if cranial or caudal angulation is used, selection of an orthogonal view can be difficult.

In conclusion, this study suggests that absolute diameter measurements are the most reproducible compared with visual and quantitative estimates of percent diameter stenosis and videodensitometric percent area both before and after PTCA. Orthogonal view studies show that single-view videodensitometric percent area is not sufficient to accurately evaluate coronary stenoses. Thus, when serial studies are undertaken, view angles should be reproduced as closely as possible.

\section{References}

1. Fisher LD, Judkins MP, Lesperance J Cameron A, Swaye P, Ryan T, Maynard C, Bourassa M, Kennedy IW, Gosselin A, Kemp H, Faxon D, Wexler L, Davis KB. Reproducibility of coronary arteriographic reading in the Coro- 
nary Artery Surgery Study (CASS). Cathet Cardiovasc Diggn 1982;8:565-575. 2. Zir LM, Miller SW, Dinsmore E, Gilbert IP, Harthorne JW. Inter-observer variability in coronary angiography. Circulation 1976;53:627-632.

3. Arnett EN, Isner JM, Redwood DR, Kent KM, Baker WP, Ackerstein J, Roberts WC. Coronary artery narrowing in coronary heart disease: comparison of cineangiographic and necropsy findings. Ann Intern Med 1979;91;35U356.

4. DeRouen TA, Murray JA, Owen W. Variability in the analysis of coronary arteriograms. Circulation 1977;55:324-328.

5. Detre KM, Wright E, Murphy ML, Iakaro T. Observer agreement in evaluating coronary angiograms. Circulation 1975;52:979-986

6. Brown GB, Bolson E, Frimer M, Dodgc HT. Quantitative coronary arteriography: estimation of dimensions, hemodynamic resistance, and atherome mass of coronary artery lesions using the arteriogram and digital computation. Circulation 1977:55:329-337.

7. LeFree MI, Simon SB, Mancini GB] Vogel RA. Digital radiographic assessment of coronary arterial geometric diameter and videodensitometric cross sectional area. Proc Soc Photo-optical Instrum Eng 1986;626:334-341.

8. LeFree MT, Simon, SB, Lewis RT, Bates ER, Vogel RA. Digital radiographic coronary artery quantification. Proc Comput Cardiol 1985;99.

9. Mancini GBIM, Simons SB, McGillem MJ, LeFree MT, Friedman HC Vogel RA. Automated quantitative coronary angiography: morphologic and physiologic validation in vivo of a rapid digital angiographic method. Girculation 1987;75:452-460.

10. Tobis , , Nalcioglu O, Isert L, Johnston WD, Rueck WD, Castleman E, Bauer $\mathrm{B}$, Montelli $\mathrm{S}$, Henry WL. Detection and quantitation of coronary artery stenoses from digital subtraction angiograms compared with 35-millimeter film cineangiograms. $\Lambda \mathrm{m}$ I Cardiol 1981;51:189-496.

11. Vas R, Eigler N, Miyazonio C, Pfaff JM, Resser KJ, Weiss M, Nivatpumin $\mathrm{T}$. Whiting J, Forrester J. Digital quantification eliminates intra-observer and inter-obserwer variability in the evaluation of coronary artery stenosis. Am Y
Cardiol 1985;56:718-723.

12. Nichols AB, Gabrieli CFO, Fenoglio II, Esser PD. Quantification of relative coronary arterial stenosis by cinevideodensitometric analysis of coronary arteriograms. Circulation 1984;69:512-522.

13. Spears JR, Sandor T, Als AV, Malagold M, Markis JE, Grossman W, Serur IR, Paulin S. Computerized image analysis for quantitative measurement of vessel diameter from cineangiograms. Circulation 1983;68:453-461.

14. Landis JR, Koch GG. A review of statistical methods in the analysis of data urising from observer reliability studies (purt I). Slatistica Neerlandica 1975;29:101-112.

15. Harrison DG, White CW, Hiratzka LF, Doty DB, Barnes DH, Eastham CL, Marcus ML. The value of lesion cross-sectional area determined by quantitative coronary angiography in assessing the physiologic significance of proximal left anterior descending coronary arterial stenoses. Circulation 1984; 69:1111-1119.

16. Harrison DG, Ferguson DW, Collins SM, Skorton DJ, Ericksen EE, Kioschos MJ, Marcus ML, White CW. Rethrombosis after reperfusion with streptokinase: importance of geometry of residual lesions. Circulation 1984:69:991999.

17. Sheehan FH, Detlef GM, Schofer J, Dodge HT, Bolson EL. Factors that determine recovery of left ventricular function after thrombolysis in patients with acute myocardial infarction. Circulation 1985;71:1121-1128.

18. Wijns W, Serruys PW, Reiber JHC, Brand M, Simoons ML, Kooijman CJ, Balakumaran K, Hugenholtz PG. Quantitative angiography of the left anterior descending corunary artery; correlations with pressure gradient and results of exercise thallium scintigraphy. Girculation 1985;71:273-279.

19. Reiber JHC, Srruys PW, Kooijman CJ, Wijns W, Slager CJ, Gerbrands II. Schuurbiers JCH, Boer AD, Hugenholtz PG. Assessment of short-, medium-, and long-term variations in arterial dimensions from computerassisted quantitation of coronary cineangiograms. Circulation 1985;71: $280-288$. 